\title{
High Mobility Group A1 (HMGA1) proteins interact with p53 and inhibit its apoptotic activity
}

\author{
GM Pierantoni ${ }^{1}$, C Rinaldo ${ }^{2}$, F Esposito ${ }^{1}$, M Mottolese ${ }^{3}$, \\ S Soddu ${ }^{2}$ and A Fusco ${ }^{*, 1,4}$ \\ 1 Dipartimento di Biologia e Patologia Cellulare e Molecolare, Facoltà di \\ Medicina e Chirurgia, Università degli Studi di Napoli 'Federico II', via S. \\ Pansini 5, 80131 Naples, Italy \\ 2 Dipartimento di Oncologia Sperimentale, Instituto Nazionale dei Tumori \\ Regina Elena, via delle Messi d'Oro 156, 00158 Rome, Italy \\ ${ }^{3}$ Servizio di Anatomia Patologica, Instituto Nazionale dei Tumori Regina Elena, \\ via Elio Chianesi 53, 00144 Rome, Italy \\ ${ }^{4}$ NOGEC (Naples Oncogenomic Center)-CEINGE, Biotecnologie Avanzate, \\ Napoli \& SEMM, European School of Molecular Medicine, Naples Site, via \\ Comunale Margherita 482, 80145 Naples, Italy \\ * Corresponding author: A Fusco, Dipartimento di Biologia e Patologia Cellulare \\ e Molecolare, Facoltà di Medicina e Chirurgia, Università degli Studi di Napoli \\ 'Federico II', via S. Pansini 5, 80131 Naples, Italy, and NOGEC (Naples \\ Oncogenomic Center)-CEINGE, Biotecnologie Avanzate, Napoli \& SEMM, \\ European School of Molecular Medicine, Naples Site, via Comunale \\ Margherita 482, 80145 Naples, Italy. Tel: + 390813722857 ; \\ Fax: + 390817463749 ; \\ E-mail: afusco@napoli.com
}

Received 01.8.05; revised 12.10.05; accepted 15.11.05; published online 09.12.05 Edited by M Oren

\begin{abstract}
HMGA gene overexpression and rearrangements are frequent in several tumours, but their oncogenic function is still unclear. Here we report of a physical and functional interaction between High Mobility Group A1 (HMGA1) protein and p53 oncosuppressor. We found that HMGA1 binds p53 in vitro and in vivo, and both proteins are present in the same complexes bound to the Bax gene promoter. HMGA1 interferes with the p53-mediated transcription of $\mathrm{p} 53$ effectors $B a x$ and p21 waf1 while cooperates with p53 in the transcriptional activation of the p53 inhibitor $m d m 2$. This transcriptional modulation is associated with a reduced p53-dependent apoptosis in cells expressing exogenous HMGA1 and p53, or in cells expressing endogenously the proteins and in which p53 was activated by UV-irradiation. Furthermore, antisense inhibition of HMGA1b expression dramatically increases the UV-induced p53-mediated apoptosis. These data define a new physical and functional interaction between HMGA1 and p53 that modulates transcription of p53 target genes and inhibits apoptosis.

Cell Death and Differentiation (2006) 13, 1554-1563.

doi:10.1038/sj.cdd.4401839; published online 9 December 2005
\end{abstract}

Keywords: apoptosis; HMGA1; p53; antibody array; UV

Abbreviations: HMGA1, High Mobility Group A1; Mdm2, murine double minute 2; CMV, cytomegalovirus

\section{Introduction}

The high mobility group A (HMGA) non-histone chromosomal HMGA1a, HMGA1b and HMGA2 proteins constitute a subgroup of HMG accessory factors that play key roles in chromatin architecture and gene control. ${ }^{1,2}$ These proteins are low molecular weight nuclear factors that interact with the minor groove of many AT-rich promoters and enhancers. ${ }^{3}$ The HMGA proteins per se do not exert transcriptional activity, but orchestrate the assembly of nucleoprotein complexes involved in gene transcription, replication, and chromatin structure through a complex network of protein-DNA and protein-protein interactions. ${ }^{4}$ The expression of HMGA proteins is high during embryogenesis ${ }^{5,6}$ and low or undetectable in normal adult tissues. High HMGA expression is a frequent feature of tumour transformation. Indeed, increased HMGA levels correlate with the appearance of a malignant phenotype in rat thyroid cells and in experimental thyroid and skin tumours. ${ }^{7-9}$ HMGA1 levels are high in human thyroid, ${ }^{10,11}$ colon, $^{12-14}$ prostate, ${ }^{15}$ pancreas, ${ }^{16}$ cervix, ${ }^{17}$ ovary $^{18}$ and breast ${ }^{19}$ carcinomas. We had previously demonstrated that overexpression of HMGA proteins is required for cell transformation, since the blockage of their synthesis prevents tumorigenic transformation of rat thyroid cells by murine transforming retroviruses. ${ }^{20,21}$ Moreover, infection with a recombinant adenovirus carrying the HMGA $1 b$ cDNA in antisense orientation led several carcinoma cell lines to death. $^{22}$

Despite the wealth of data associating aberrant- or overexpression of HMGA1 proteins with cancer, little is known about the molecular roles by which HMGA1 proteins exert their tumorigenic effect.

The tumour suppressor protein p53 is the most frequently altered gene in human cancers. Besides contributing to tumorigenesis, loss or inactivation of p53 is also involved in the development of tumour resistance to chemo and radiotherapy. p53 was originally defined as the 'guardian of the genome' based on its functions in the prevention of genetic instability. ${ }^{23}$ However, accumulating evidence indicates that the p53 apoptotic function is the most relevant for both tumorigenicity and induction of tumour-resistance to antineoplastic treatments. ${ }^{24-26}$ The apoptotic activity of p53 can be regulated independently of the cell cycle arrest function, and several proteins have been identified that are necessary for p53 to mediate the full apoptotic response, and so show efficient tumour suppressor activity. ${ }^{24}$

Here we show that HMGA1 interacts with the p53 tumour suppressor and interferes with its proapoptotic activity. We demonstrate that HMGA1 and p53 are present in the same multiprotein complexes bound to the Bax promoter and that HMGA1 modifies the p53 transcriptional activity on p53 target genes (i.e. Mdm2, Bax, and $p 21^{\text {waf1 }}$ ). Furthermore, HMGA1 strongly interferes with p53-induced apoptosis, suggesting 
that HMGA1 overexpression can contribute to tumorigenic transformation by counteracting the apoptotic function of the p53 tumour suppressor.

\section{Results}

\section{HMGA1 physically interacts with p53}

In order to identify new HMGA1-interacting proteins, we employed an antibody array containing hundreds of high quality antibodies against well-studied proteins, involved in cell cycle regulation, apoptosis, and signal transduction. The membrane-immobilized antibodies retain their capabilities of recognizing and capturing antigens. The array was incubated with a total cell extract from 293 cells transfected with the full-length Hmga1b cDNA tagged with the influenza virus HA epitope, and immunoblotted with anti-HA antibody. The results indicated interaction between HMGA1b and various proteins (data not shown); among these, we selected the oncosuppressor p53 because of its relevance in tumour development.

To verify whether HMGA1b interacts with p53, we evaluated the binding between the two purified proteins in vitro. His-p53 protein was allowed to bind to the His-HMGA1b protein, and the complexes were immunoprecipitated with anti-p53 or anti-HMGA1 Abs and analysed by Western blotting with anti-HMGA1 or anti-p53 Abs, respectively. As shown in the Figure 1a, the two proteins can directly interact.

To examine further the specificity of this interaction and to map the HMGA1b regions required for binding to $p 53$, we generated a series of $\mathrm{NH}_{2}-$ and $\mathrm{COOH}$-terminal deletion mutants of Hmga1b. The resulting cDNAs were HA-tagged by cloning into the pCEFL-HA expression vector (Figure 1b). These vectors were transiently transfected into 293 cells that were harvested $48 \mathrm{~h}$ later. The protein extracts were tested for their interaction with bacterially expressed p53 fused to glutathione $S$-transferase (GST). The complexes were immobilized on glutathione-Sepharose matrix. The bound

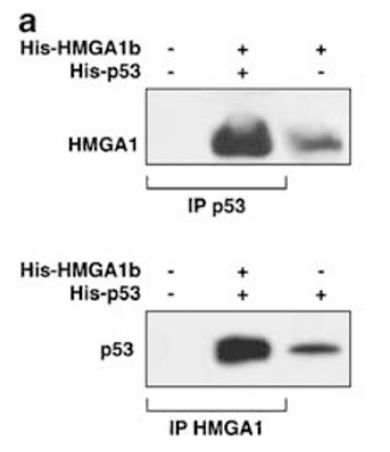

d

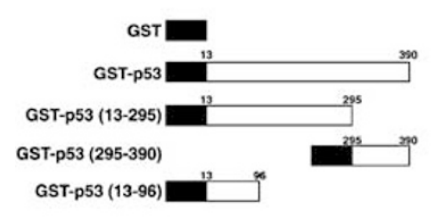

b

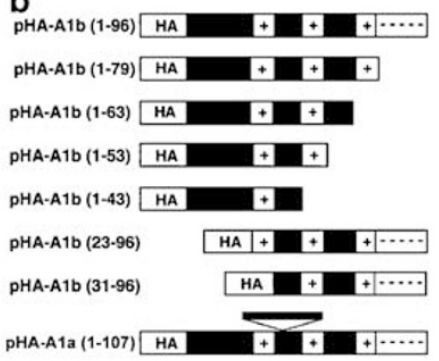

e

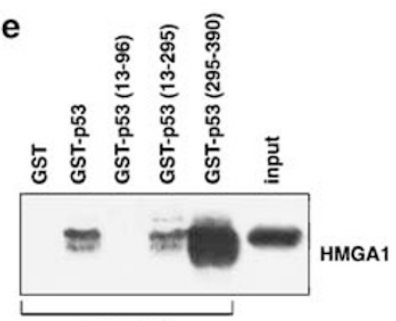

pull-down

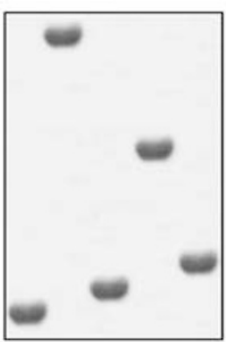

Blue coomassie
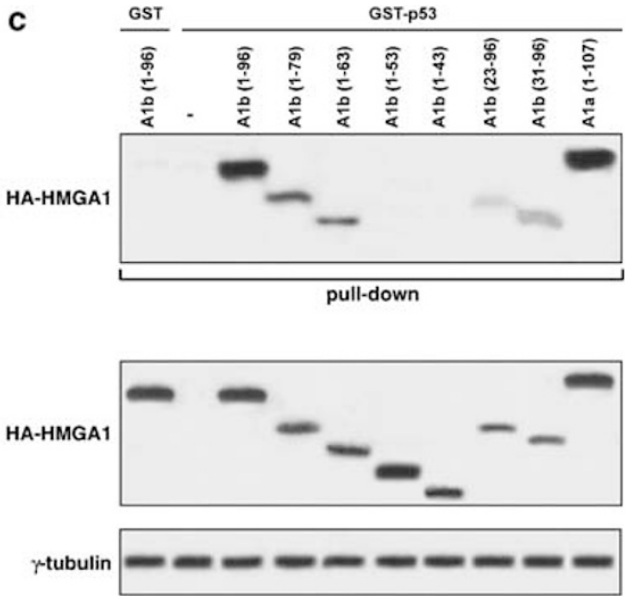

\section{rand}

Figure 1 In vitro interaction between HMGA1 and p53. (a): The in vitro interaction between $\mathrm{p} 53$ and HMGA1b was assessed by immunoprecipitation assay with antip53 (upper panel) or anti-HMGA1 (lower panel) antibodies and blotting with the reciprocal antibodies after preincubation of the two proteins. The relative inputs are the His-HMGA1b and His-p53 recombinant proteins loaded as controls. (b) Diagram of the HA-tagged Hmga1 deletion mutants used in co-immunoprecipitation experiments. The AT-hook domains (+) and the acidic tail (-.---) are indicated. (c) 293 cells were transiently co-transfected with the indicated plasmids carrying the HA-Hmga1 wild type or deletion mutants. GST pull-down assays were performed between total cell extracts (TCEs) from pHA-Hmga 1 mutants transfected cells and the GST-p53 fusion protein. The bound complexes (upper panel) and TCEs (lower panel) were separated on SDS-PAGE and analysed by Western blotting with anti-HA antibody or anti- $\gamma$ tubulin antibody, as a loading control. (d) Schematic representation of GST-p53 fusion proteins used in this study. (e) GST pull-down assay of the indicated GST-fusion proteins with recombinant HMGA1b protein. The bound complexes were separated by SDS-PAGE, and the filter was incubated with anti-HMGA1 antibodies (upper panel). Gels were stained with blue-Coomassie to show equal amount of the GST-fusion protein used in the assay (lower panel) 
proteins were separated by SDS-PAGE, blotted, and the filters were immunoreacted with anti-HA antibody. As expected, full-length HMGA1b protein binds to GST-wtp53 (Figure 1c). Deletion of the carboxy-terminal tail (pHA-A1b/ 1-79) and of the third AT-hook domain (pHA-A1b/1-63) did not impair the binding of HMGA1b to p53. In contrast, the HMGA1b/p53 interaction did not occur in the absence of the region between the second and the third $A T$-hook (amino acids 54-63, construct pHA-A1b/1-53) or in the presence of the first 43 amino acids encompassing only the first AT-hook (construct $\mathrm{pHA}-\mathrm{A} 1 \mathrm{~b} / 1-43$ ). The $\mathrm{NH}_{2}$-terminal truncations of HMGA1b (constructs pHA-A1b/23-96 and pHA-A1b/31-96) were also involved in the HMGA1b/p53 interaction, as demonstrated by the reduced binding to $p 53$ of the HMGA1b mutants versus the wild-type protein (Figure 1c). Thus, the region between the second and the third $A T$-hook and the amino-terminus of HMGA1b protein take part in p53 binding. Finally, we have also analysed the interaction between the long HMGA1a isoform, which has and extra stretch of 11 aa between the first and the second AT-hook domains, and p53. To this aim, we transiently overexpressed the pHA-A1a/1-107 construct, and performed a pull-down assay with GST alone (data not shown) and GST-p53. As shown in Figure 1c, also the HMGA1a isoform is able to bind p53 protein.

To identify the p53 domain involved in the interaction with HMGA1b, pull-down assays were performed with recombinant HMGA1b protein and a series of p53 deletion mutants fused to GST (Figure 1d). Only the recombinant polypeptide GST-p53(13-96) does not bind HMGA1b protein (Figure 1e), whereas the other mutants tested, the GST-p53(295-390) and the GST-p53(13-295) proteins, bind HMGA1b. Noteworthy, the GST-p53(295-390) C-terminal domain binds more efficiently than the full-length or the GST-p53(13-295) proteins do. No HMGA1b was detectable in the complexes obtained with the GST protein alone (Figure 1e, upper panel). Gels were stained with blue-Coomassie to show the equal amount of GST-fusion protein used for the pull-down assay (Figure 1e, lower panel). These results suggest that the $\mathrm{N}$-terminal domain of p53, which comprises the transactivation and the proline-rich domains, is not involved in the binding, while the DNA binding (aa 102-292) and the C-terminal domain, which comprises the tetramerization (aa 323-356) and the regulatory (363-393) domains, are independently able to bind HMGA1b, with the C-terminal domain itself binding more efficiently than the full-length or the DNA binding domain alone.

\section{HMGA1b interacts with p53 in vivo}

To verify the interaction between HMGA1b and $\mathrm{p} 53$ in vivo, total cell extracts (TCE) from 293 cells transiently transfected with $\mathrm{pCMV} / \mathrm{Hmga} 1 \mathrm{~b}$ and $\mathrm{pCMV} / \mathrm{p} 53$ were immunoprecipitated with anti-p53 monoclonal $\mathrm{Ab}$ and analysed by Western blotting with anti-HMGA1 polyclonal $\mathrm{Ab}$. Larger amounts of HMGA1 protein were present in the immunocomplexes from cells transfected with the two expression plasmids (Figure 2a, upper panel). The reciprocal experiment performed immunoprecipitating with anti-HMGA1 $\mathrm{Ab}$ and revealing with anti-p53 $\mathrm{Ab}$ confirmed the interaction (Figure $2 \mathrm{a}$, lower panel). We could detect this association also between the endogenous proteins (Figure 2b), demonstrating that HMGA1 and p53 form complexes in vivo.

To further verify the specificity of the interaction between HMGA1 and p53 proteins, we performed co-immunoprecipitation experiments also in $\mathrm{p} 53^{-/-} \mathrm{H} 1299$ cells transfected with the relative expression constructs. The extracted proteins were immunoprecipitated with anti-HMGA1 or anti-p53 antibodies, and the filters were incubated with the relative antibody. The results shown in Figure $2 \mathrm{c}$ demonstrate that the interaction occurs only in cells expressing both proteins.

\section{HMGA1 and p53 are present in the protein- complexes bound to the bax promoter}

p53 is a sequence-specific transcription factor whose DNAbinding consensus is present in a large number of promoters. ${ }^{25}$ HMGA1 proteins are DNA-binding factors that interact
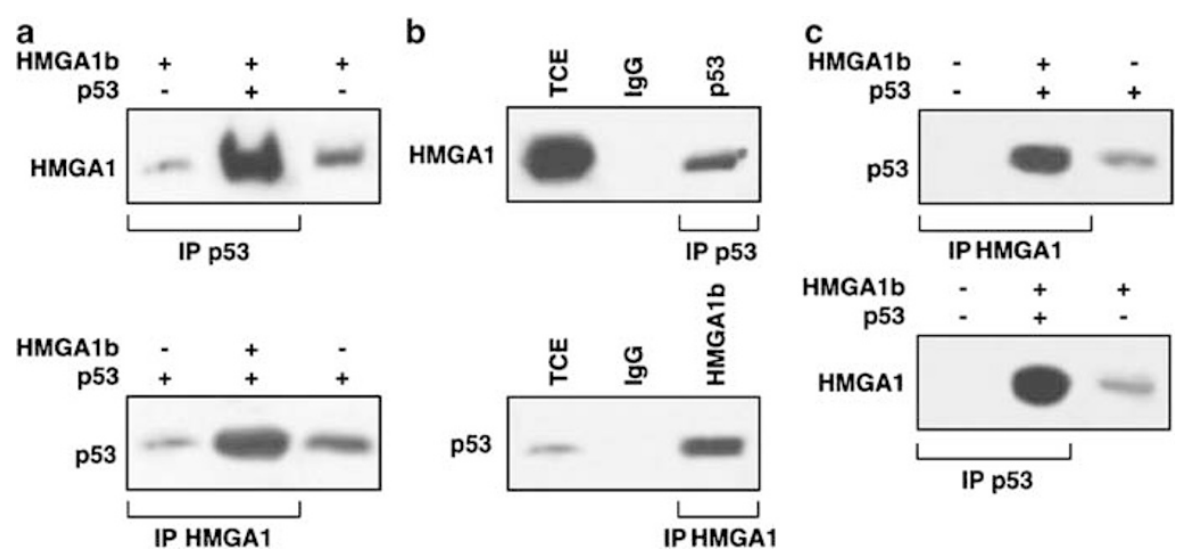

Figure 2 In vivo characterization of the HMGA1/p53 interaction. (a) 293 cells were transfected with $\mathrm{pCMV} / \mathrm{Hmga} 1 \mathrm{~b}$ vector alone or together with $\mathrm{pCMV}$ - $\mathrm{p53}$. After $48 \mathrm{~h}$, total cell extracts were prepared and equal amounts of proteins were immunoprecipitated with anti-p53 (upper panel) or anti-HMGA1 (lower panel) antibodies, and the immunocomplexes analysed by Western blotting using the reciprocal antibodies. The relative inputs are total cell extracts derived from 293-transfected cells with the expression vector encoding HMGA1b or p53 protein, respectively. (b) The co-immunoprecipitation was performed as in (a) but on the endogenous p53 and HMGA1 proteins (TCE from parental 293 cells). IgG indicates the negative control of immunoprecipitation using an unrelated antibody. (c): Co-immunoprecipitation with the antiHMGA1 or anti-p53 antibodies of untransfected or pCMV/Hmga1b and pCMV-p53 transfected H1299 cells 
with the minor groove of many promoters and enhancers. ${ }^{3}$ Thus, we asked whether the physical interaction between HMGA1 and p53 takes place on promoter regions of p53 targets. The human Bax gene promoter was selected because its region spanning nucleotides -441/-500 (hbaxpr) contains the p53-binding site and an AT-rich putative HMGA1binding site. We first evaluated whether HMGA1 binds this 60 bp promoter region by EMSA. As shown in Figure $3 \mathrm{a}, 50 \mathrm{ng}$ of recombinant His-HMGA1b protein were able to bind the ${ }^{32} \mathrm{P}$-end-labelled double-strand Bax promoter oligonucleotide. Binding specificity was demonstrated by competition experiments showing loss of binding with the addition of a 100-fold molar excess of unlabelled Bax promoter oligonucleotide. We have also demonstrated that for the binding of HMGA1b protein to the Bax promoter region is not required the p53binding site, as demonstrated by an EMSA assay performed with the same oligonucleotide deprived of the p53-binding site (hbaxprdel).
Next, we evaluated whether HMGA1 protein binds the Bax promoter in vivo by performing ChIP assays. The binding of p53 was used as a positive control. p53-null H1299 cells were transfected with $\mathrm{p} 53$ and/or HMGA1b, tested by Western blotting for protein expression (Figure 3b), crosslinked, and immunoprecipitated with anti-HMGA1, anti-p53, or anti-IgG antibodies. Immunoprecipitation of chromatin was then analysed by semiquantitative PCR, using primers spanning the $-250 /-530$ region of the Baxpromoter. As expected, antip53 precipitated this Bax region from $\mathrm{H} 1299$ cells transfected with p53 alone or with overexpressed-HMGA1b protein (Figure 3c). Occupancy of this Bax region by HMGA1 was clearly detectable in anti-HMGA1-precipitated chromatin from untransfected or from $\mathrm{H} 1299$ cells overexpressing p53 alone (Figure 3c), being endogenous HMGA1 protein expressed in H1299 cells, and even more in cells overexpressing both p53 and HMGA1b exogenous proteins. No precipitation was observed with anti-IgG precipitates, and when primers for

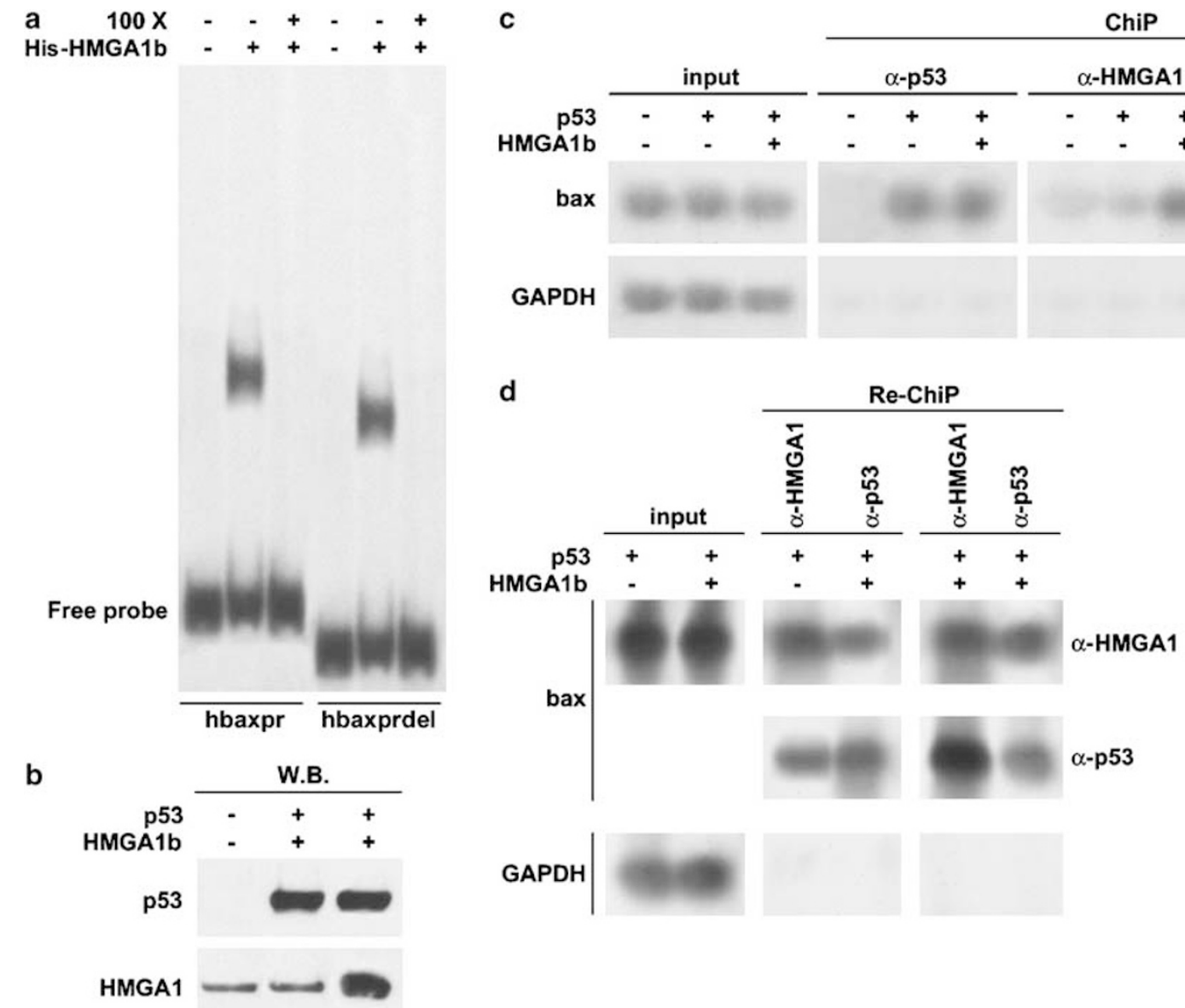

Figure 3 HMGA1 binds the human Bax promoter in vitro and in vivo. (a) EMSA performed with a radiolabelled oligonucleotide spanning from $\mathrm{nt}-441$ to -500 of the human Bax promoter (hbaxpr) and the same region deprived of p53-binding site (hbaxprdel) incubated with $50 \mathrm{ng}$ of recombinant HMGA1b protein. To assess the specificity of the binding, His-HMGA1b protein was incubated in the presence of a 100-fold excess of unlabelled oligonucleotide used as competitor. (b) Cellular extracts derived from untransfected or p53 and/or HMGA1b overexpressing H1299 cells used for ChIP experiments were analysed by Western blotting. (c) Soluble chromatin from $\mathrm{H} 1299$ cells transfected with p53 alone or in combination with HMGA1b was immunoprecipitated with anti-p53 or anti-HMGA1. The DNAs were then amplified by semiquantitative PCR using primers that cover a region of human Bax promoter (-250/-530), which contains the p53-binding sites. As an immunoprecipitation control, IgG was used. The panel shows PCR amplification of the immunoprecipitated DNA using primers for the GAPDH gene promoter. (d) In Re-ChIP experiments, soluble chromatin from transfected $\mathrm{H} 1299$ cells was immunoprecipitated with anti-p53, eluted, and reimmunoprecipitated with anti-HMGA1. The purified DNA was used as template for PCR with primers that amplify the $-250 /-530$ human Bax promoter region 
the control promoter GAPDH were used (Figure 3c, lower panel), indicating that the binding is specific for the Bax promoter. These results indicate that HMGA1 protein binds the Bax promoter region in vivo, and that the binding occurs also in absence of p53 protein.

To determine whether HMGA1 occupies the Bax promoter together with p53, the anti-HMGA1 complexes were released, reimmunoprecipitated with anti-p53, and then analysed by semiquantitative PCR (Re-ChIP). The results show that the antibodies against p53 precipitate the Bax promoter after their release from anti-HMGA1, indicating that HMGA1 occupies this region with p53 (Figure $3 d$ ). The reciprocal experiment provided comparable results (Figure $3 d$ ). Taken together, these results indicate that HMGA1 binds the human Bax promoter in vitro and in vivo, and participate to the same DNAbound complexes that contain p53.

\section{HMGA1b modulates p53-mediated transcriptional activity}

p53 regulates the transcription of several genes whose products can trigger a variety of antitumour functions. ${ }^{27,28}$ To evaluate the effect of HMGA1 expression on p53-mediated transcription, p53-null $\mathrm{H} 1299$ cells were co-transfected with expression vectors encoding HMGA1b and p53, and with reporter vectors carrying the luciferase gene under the control of various p53-responsive promoters, that is, $m d m 2, p 21^{\text {waf1 }}$, and Bax. As shown in Figure 4, in the presence of HMGA1b, p53 has increased transcriptional activity on the promoter of its inhibitor MDM2, whereas has showed a strongly reduced activity on the promoter of its effectors Bax and p21 waf1. The effects exerted on the $m d m 2$ and Bax promoters were dosedependent, whereas the effect on $p 21^{\text {waf1 }}$ was maximal even at the lowest HMGA1b concentration used. HMGA1b expression alone did not affect the activity of any promoter; hence, it acts in the regulation of these promoters only cooperating with p53 protein. We next tested whether the effects of HMGA1 overexpression in combination of $\mathrm{p} 53$ reflected in changes in the endogenous levels of Bax, Mdm2, and p21 proteins. As shown in Figure 4d, Bax protein levels were significantly elevated in cells expressing p53 alone, compared with control cells, while HMGA1 alone had no effects on Bax levels. However, co-expression of HMGA1 with p53 resulted in a significant decrease in Bax levels compared with p53 only expressing cells. Similar results were obtained evaluating endogenous p21, while Mdm2 is increased from p53 expression, and further increased when both HMGA1 and p53 are overexpressed. These results indicate that HMGA1b cooperates in p53-mediated transcription of the $\mathrm{mdm} 2$ promoter while represses that of the $p 21^{\text {waf1 }}$ and Bax promoters, suggesting that modulation of p53 transcriptional activity by HMGA1b is promoter-specific, at least in the case of H1299 cells.

\section{HMGA1 represses p53 apoptotic function}

To evaluate the effects exerted by HMGA1 on the biological activity of p53, we infected $\mathrm{H} 1299$ cells, which express HMGA1 but are null for p53 expression, with a recombinant adenovirus carrying the wtp53 gene (Adp53) or the empty control vector (dl70.3), with or without overexpressed HMGA1b. The percentages of TUNEL positive cells were measured $36 \mathrm{~h}$ postinfection/transfection. As expected, exogenous p53 expression induced apoptotic cell death in these cells (Figure 5a). However, when HMGA1b was concomitantly overexpressed with p53, the percentage of TUNEL positive cells was strongly reduced (Figure 5a), suggesting that HMGA1b might interfere with p53 apoptotic function. Interestingly, HMGA1b overexpression in the absence of p53 did not suppress the basal level of TUNEL positivity induced by the control adenovirus infection, which was rather mildly increased (Figure 5a), supporting the hypothesis that HMGA1b inhibits the p53-dependent apoptosis. Similar results were obtained by concomitantly overexpressing the wtp53 gene (Adp53) and the long HMGA1a isoform, as evaluated measuring the percentage of cell death by Trypan blue exclusion test (Figure $5 b$ ).

To verify the antiapoptotic activity of HMGA1b in a more physiological context, we exposed the wtp53-carrying HCT116 cells, which express HMGA1 and p53, to UV irradiation to activate the endogenous p53 in the presence or absence of overexpressed HMGA1b. As shown in Figure 5c, HMGA1b overexpression strongly repressed UVinduced TUNEL positivity. Complementary results were observed when HCT116 or RKO cells, another colon cancer cell line also expressing HMGA1 and p53 similar to the HCT116 cells, were treated with specific antisense oligodeoxynucleotides (AS) to reduce the endogenous HMGA1b expression. As shown in Figure 5d, AS-treatment reduced HMGA1b expression in both cell lines (upper panels) and was associated with an increased sensitivity to UV-induced, p53mediated apoptosis (lower panels).

To further assess the p53 dependency of the HMGA1b antiapoptotic activity, the isogenic HCT116 system, which includes the $\mathrm{p} 53(+/+)$ and the $\mathrm{p} 53(-/-)$ cells, $^{29}$ was employed. Cells from both lines were exposed to UV irradiation in the presence or absence of overexpressed HMGA1b, and their percentages of death measured by Trypan blue exclusion test. Similar to the results obtained by TUNEL assay (Figure 5c), HMGA1b overexpression significantly reduced the amount of cell death induced by UV irradiation in the $\mathrm{p} 53(+/+)$ cells (Figure 5e, black bars). However, no modification of death rate by HMGA1b overexpression was observed in the p53(-/-) isogenic cells, although a small amount of UV-induced, p53-independent death was present in these latter cells (Figure 5e, grey bars), strongly suggesting that the antiapoptotic effect of HMGA1b depends on its activity on p53.

Taken together, these data indicate that HMGA1 can functionally interfere with the apoptotic function of the p53 oncosuppressor.

\section{Discussion}

HMGA protein overexpression and gene rearrangements are a frequent event in several human cancers. We employed an antibody array screening to get clue on the mechanisms of HMGA tumorigenesis. Here, we report a novel interaction 
a

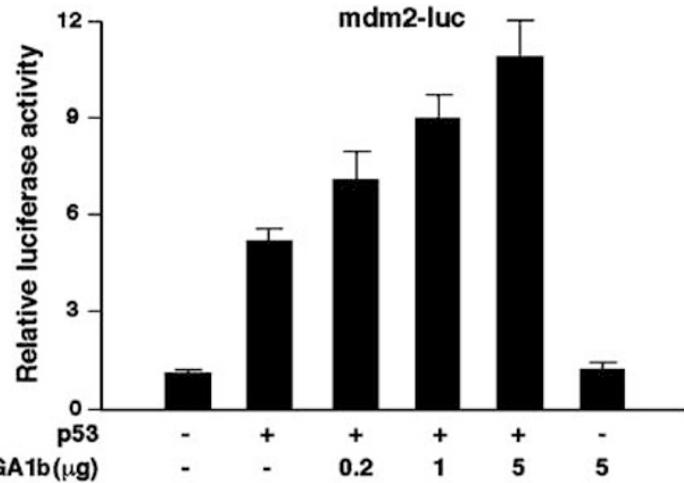

HMGA1b $(\mu \mathrm{g})$
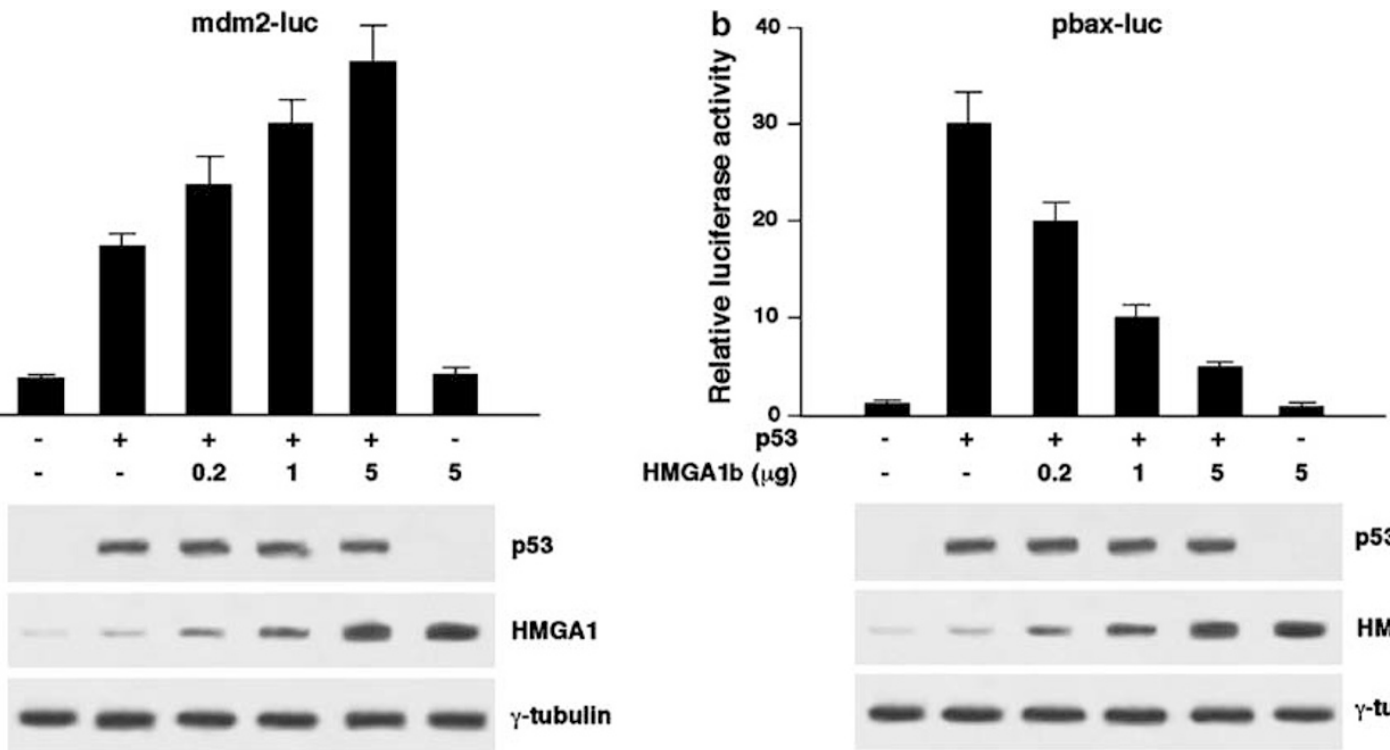

HMGA1b $(\mu \mathrm{g})$
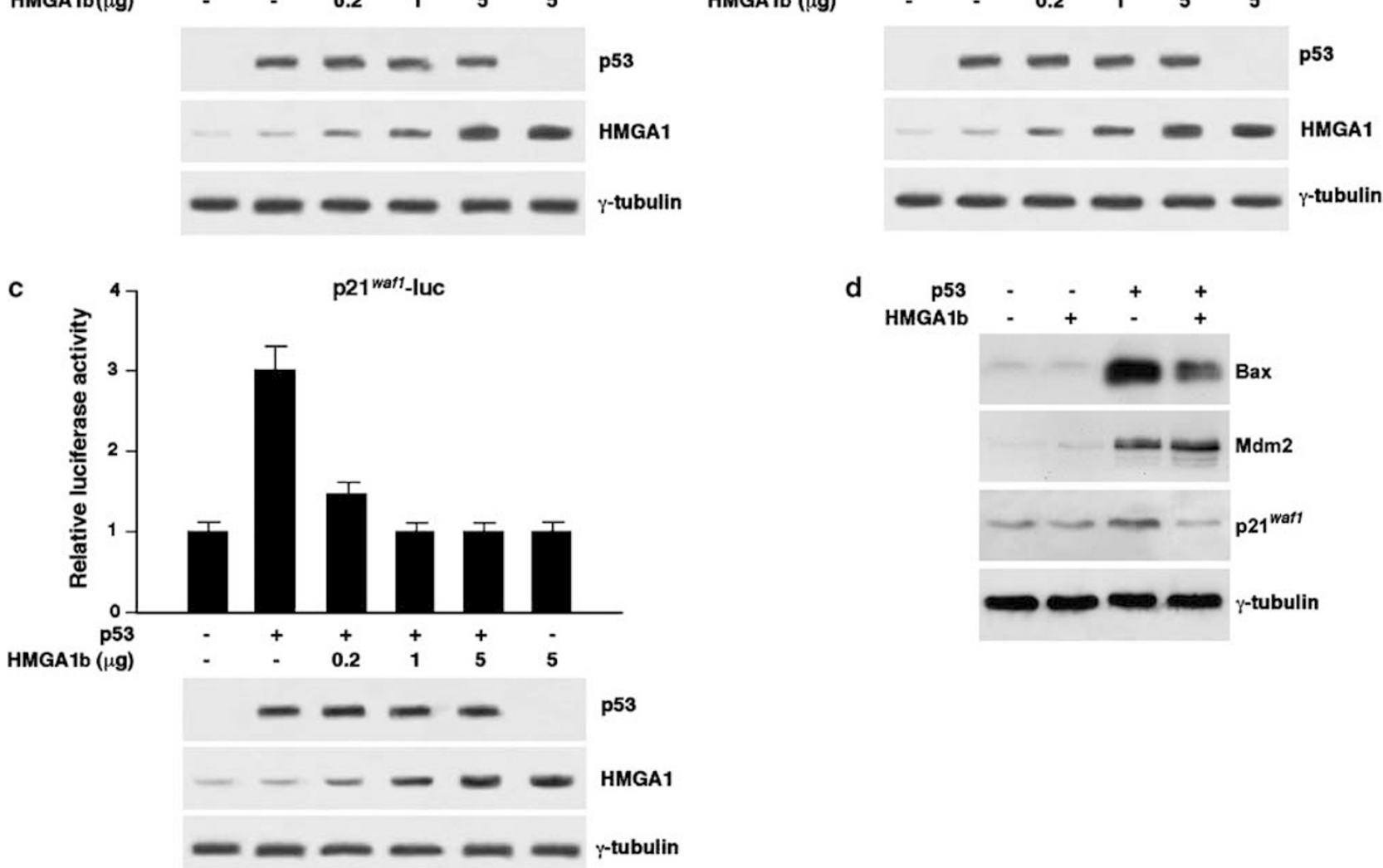

d

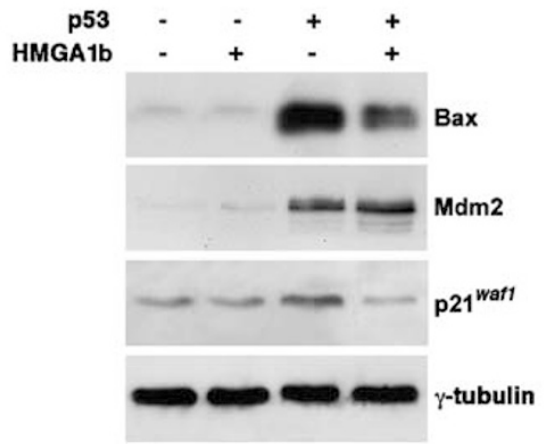

Figure 4 HMGA1b modulates p53 transcriptional activity. Dose-response analysis of increasing amounts of HMGA1b on p53 activity on the mdm2 (a), Bax (b), and p21 ${ }^{\text {waff }}$ (c) luciferase-reporter vectors transiently transfected in p53-null H1299 cells. All transfections were performed in duplicate and the data are means \pm S.D. of five independent experiments. Insert-less vectors were used as control. Western blot analyses of p53 and HMGA1 proteins from one indicative experiment are shown in the lower panels. $\gamma$-Tubulin was used to equalize protein loading. Expression of the endogenous HMGA1 protein is detectable in the insert-less vector transfected H1299 cells. (d) Endogenous protein levels of Bax, Mdm2 and p21 in the same total cellular extracts used in one representative luciferase assays

between HMGA1 and the tumour suppressor p53 that results in the inhibition of p53 apoptotic activity.

We found that both the HMGA1a and HMGA1b isoforms bind p53 protein. Moreover we have mapped the regions of HMGA1 and p53 involved in the binding. We have identified that the 54-63 amino-acid region between the second and the third AT-hooks of HMGA1b is required for its interaction with p53, while the p53 domain principally involved in the binding to HMGA1b are the C-terminal region and the DNA-binding domain. Indeed, we observed that the $\mathrm{C}$-terminal domain itself binds more efficiently than the full-length p53 or the DNA binding domain alone. Since an intramolecular regulatory domain is included in the C-terminus of $\mathrm{p} 53,{ }^{30}$ a possible interpretation of our results is that conformational changes, such as those mediated by the regulatory region over the DNA-binding domain, might modify the p53/HMGA1 interaction. Further analyses are required to elucidate this issue.

We have demonstrated that HMGA1 overexpression modifies the transcriptional activity of p53 by activating the transcription of the p53 inhibitor Mdm2, and repressing the p53 effector genes Bax and $p 21^{\text {waf1 }}$. At biological level, these transcriptional modifications were associated with a strong inhibition of the p53 apoptotic activity, strongly supporting the hypothesis that HMGA1 contributes to tumour transformation 
a

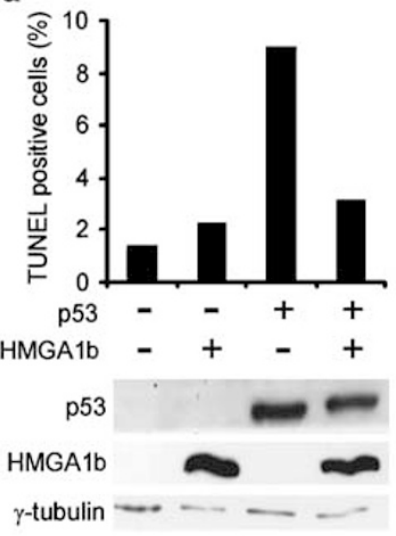

b

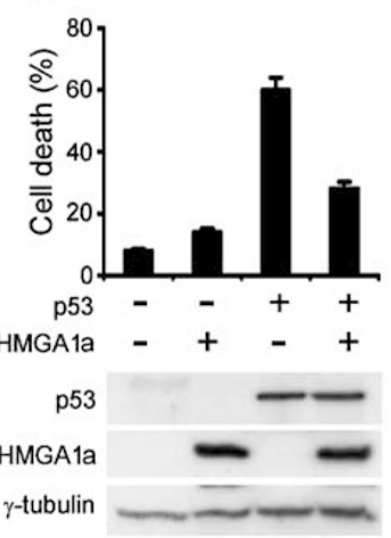

C

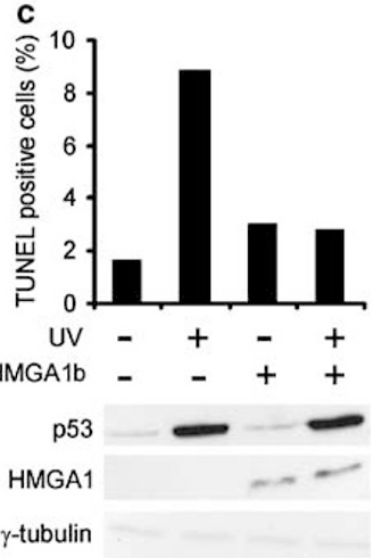

d
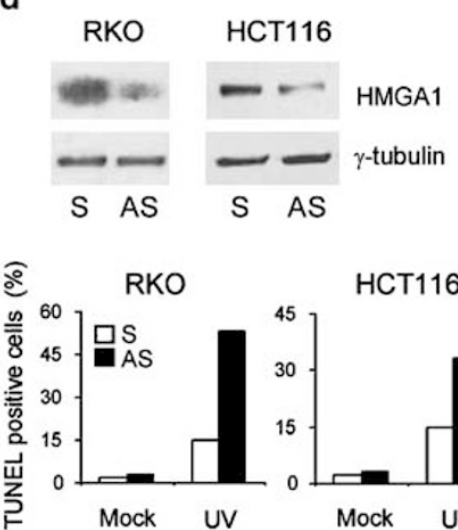

HCT116

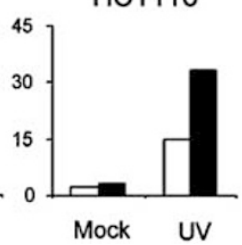

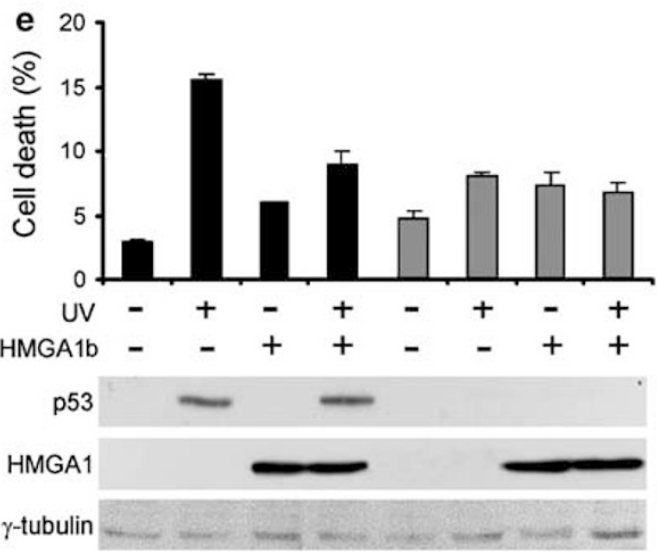

Figure 5 HMGA1 interferes with the apoptotic activity of p53. (a) p53 null H1299 cells were infected with the control vector d170.3 (- in the p53 row) or with the wtp53carrying Adp53 ( + in the p53 row). At $1 \mathrm{~h}$ postinfection, cells were transfected with the pCMV control vector ( - in the HMGA1b row) or the pCMV/Hmga1b vector $(+$ in the HMGA1b row). After $48 \mathrm{~h}$, both floating and adherent cells were spun onto slides and analysed by TUNEL assay. The percentage of TUNEL-positive cells of one indicative experiment out of four is reported. The expression of the indicated proteins was analysed by Western blotting. (b) p53-null $\mathrm{H} 1299$ cells were infected as in (a). At $1 \mathrm{~h}$ postinfection, cells were transfected with the pCEFL control vector ( - in the HMGA1 row) or the pCEFL-Hmga1a vector (+ in the HMGA1 row). After $48 \mathrm{~h}$, both floating and adherent cells were collected and analysed by Trypan blue exclusion. Expression of the indicated proteins was analysed by Western blotting; the result of one of three experiments performed is reported. (c) wtp53-carrying HCT116 cells were irradiated or not ( + and - , respectively, in the UV row) with $50 \mathrm{Jm}^{-2}$ of UV to activate the endogenous p53. The percentage of cell death and the protein levels were analysed as in (a). Mean \pm S.D. of three independent experiments are shown. Cells from the same sample were analysed by TUNEL as described in (a). (d) RKO and HCT116 cells were transduced with HMGA1b-specific sense (S) or antisense (AS) oligonucleotides. After $24 \mathrm{~h}$, cells were mock or UV-irradiated $\left(50 \mathrm{~J} \mathrm{~m}^{-2}\right)$. TUNEL assay was performed $24 \mathrm{~h}$ postirradiation. After $48 \mathrm{~h}$, TCEs were analysed by Western blotting for HMGA1 expression; $\gamma$-tubulin was used loading control. (e) wtp53-carrying HCT116 cells (black bars) and p53(-/-) isogenic cells (grey bars) were irradiated or not ( + and - , respectively, in the UV row) with $50 \mathrm{~J} \mathrm{~m}^{-2}$ of UV to activate the endogenous p53. After $48 \mathrm{~h}$, both floating and adherent cells were collected and analysed by Trypan blue exclusion. Means \pm S.D. of four independent experiments are shown. The expression of the indicated proteins was analysed by Western blotting

by interfering with the apoptotic function of $\mathrm{p} 53$. We also observed that HMGA1 protein is present on the same complexes containing p53 and bound to the Bax promoter. Despite the negative action of HMGA1 on p53 transcriptional activity on this promoter, we found that HMGA1 does not decrease the occupancy of p53 to this region. At this time, we cannot completely explain the mechanism by which HMGA1 binding to the Bax promoter interferes with its p53-mediated activation. The possibility that binding of HMGA1 proteins to the DNA could somehow impair the activity of either positive regulatory proteins of the Bax promoter or basal transcription machinery is actually under investigation. An in silico analysis of the p53-responsive $m d m 2$ and $p 21^{\text {waf1 }}$ promoters that we investigated in this study also revealed the presence of several putative binding sites for HMGA1 protein, suggesting a regulation similar to that observed on the Bax promoter.

Defects in apoptosis are thought to play a major role in tumorigenesis as well as in the response of tumours to anticancer treatments. The finding that HMGA1 can bind to p53 and inhibit its apoptotic activity strongly suggests that HMGA1 contributes to tumorigenicity by inactivating the tumour-suppressing function of p53. Consistent with this hypothesis is the observation that at least two tumour histotypes with elevated HMGA expression (i.e. thyroid and prostate cancers $)^{31,32}$ have a very low frequency of mutations in the TP53 gene. This suggests that inhibition of p53 activity by the presence of HMGA1 proteins might diminish the pressure for direct TP53 gene mutations. 
Physical and functional interactions between p53 and members of other subfamilies of HMG proteins, such as the HMGB proteins, have been previously described. ${ }^{33,34}$ However, the different subfamilies possess divergent functions. ${ }^{35}$ Indeed, the reported HMGB-mediated modulation of p53 transcriptional activity seems to be relevant in normal conditions while the HMGA1-mediated inhibition of p53 apoptotic function, which we are reporting here, might be mostly relevant for tumour formation. This hypothesis is consistent with the presence, in adult life, of HMGA1 only in tumour tissue.

In conclusion, our data strongly support the existence of a new mechanism of p53 inactivation through HMGA1mediated modification of the p53 transcriptional activity. This mechanism might have important implications in tumorigenicity as well as in the development of tumour resistance to antineoplastic treatments.

\section{Materials and Methods}

\section{Cell cultures, transfections and transactivation assays}

HEK 293, HCT116, RKO and H1299 cells were maintained in Dulbecco's modified Eagle's medium (DMEM), supplemented with $10 \%$ foetal calf serum (GIBCO-BRL, Life Technologies, Gaithersburg, Maryland, United States of America), glutamine and antibiotics. Human HCT116 colorectal adenocarcinoma cells and the p53-/- derivatives were kindly provided by $B$ Vogelstein. ${ }^{29}$ Cells were transfected with plasmids by lipofectamineplus reagent or with oligonucleotides by oligofectamine reagent (Invitrogen), as suggested by the manufacturer. Cells were transiently transfected with the reporter vectors indicated and previously described, ${ }^{36}$ and normalized with the use of a co-transfected $\beta$-galactosidase construct. Luciferase activity was analysed by Dual-Light System (Applied Biosystems, Massachusetts, USA).

For the inhibition of HMGA1b expression, antisense and the corresponding sense oligonucleotides have been designed and synthesized specifically by BIOGNOSTIK (Göttingen, Germany). Oligonucleotides were added once at a concentration of $2 \mu \mathrm{M}$.

\section{Expression constructs}

The $\mathrm{pCMV} / \mathrm{Hmga} 1 \mathrm{~b}$ is described elsewhere. ${ }^{37}$ pHemagglutinin (pHA)tagged Hmga1 expression plasmids containing the entire or various portions of the Hmga1 coding sequence were amplified and inserted into the pCEFL-HA expression vector (kindly provided by Dr. S Gutkind): pHA$\mathrm{A} 1 \mathrm{~b}$ (amino acids 1-96) is constituted by the entire coding sequence of the HMGA1b isoform; $\mathrm{PHA}-\mathrm{A} 1 \mathrm{~b} / \mathrm{T}$ is constituted by the first 79 amino acids including the three AT-hook domains; $\mathrm{pHA}-\mathrm{A} 1 \mathrm{~b} / 1-63$ is constituted by the first 63 amino acids including the first two AT-hook domains and the region between the second and the third AT-hook domains; pHA-A1b/1-53 is constituted by the first 53 amino acids including the first two AT-hook domains; $\mathrm{pHA}-\mathrm{A} 1 \mathrm{~b} / 1-43$ is constituted by the first 43 amino acids including the first AT-hook domain and the region between the first and the second AT-hook domains; pHA-A1b/23-96 contains the Hmga1b coding sequence deprived of the first 23 amino acids; pHA-A1b/31-96 contains the Hmga1b coding sequence deprived of the first 31 amino acids that include the first AT-hook domain; pHA-A1a (amino acids 1107) is constituted by the entire coding sequence of the long HMGA1a isoform.

\section{In vitro translation and protein-protein binding}

The pCAG-p53, pGST-p53, pGST-p53(13-96), pGST-p53(13-295), pGSTp53(295-390) and pET2c-HMGA1b constructs are previously described (36 and 19, respectively). GST fusion proteins and His recombinant proteins were produced in Escherichia coli BL21 cells. Stationary phase cultures of $E$. coli cells transformed with the plasmid of interest were diluted $5-400 \mathrm{ml}$ in LB with ampicillin $(100 \mu \mathrm{g} / \mathrm{ml})$, grown at $30^{\circ} \mathrm{C}$ to an $\mathrm{OD}_{600}$ of 0.6 and induced with $0.1 \mathrm{mM}$ IPTG. After an additional $2 \mathrm{~h}$ at $30^{\circ} \mathrm{C}$, the cultures were harvested and resuspended in $10 \mathrm{ml}$ of cold PBS (140 mM NaCl, $20 \mathrm{mM}$ sodium phosphate (pH 7.4)), $1 \mathrm{mM}$ phenylmethylsulfonyl fluoride (PMSF) and protease inhibitors (Boehringer). The cells were broken by French Press. For the GST proteins, the supernatant was then incubated at $4^{\circ} \mathrm{C}$ for $1 \mathrm{~h}$ with $250 \mu$ l of glutathione-Sepharose beads (Amersham Pharmacia Biotech). The resin was washed with PBS and protease inhibitors. The recombinant proteins were eluted with a buffer containing PBS, $10 \mathrm{mM}$ reduced glutathione, and 10\% (v/v) glycerol. For the His-HMGA1b protein, the supernatant was purified by using nickelagarose beads supplied with the His-Trap purification kit (Amersham Pharmacia) following the manufacturer's instructions, eluted with $500 \mathrm{mM}$ imidazol and dialysed in PBS. The purified p53 protein was purchased from Li StarFISH (Carugate, Milan). The recombinant proteins were subjected to in vitro protein-protein binding. The proteins were incubated with total cellular extracts (TCEs) or other recombinant protein in NETN buffer (20 mM Tris- $\mathrm{HCl}$, pH 8.0, $100 \mathrm{mM} \mathrm{NaCl}, 1 \mathrm{mM}$ EDTA, and $0.5 \%$ Nonidet $\mathrm{P}-40$ ) for $1 \mathrm{~h}$ at $4^{\circ} \mathrm{C}$. The resins were then extensively washed in the same buffer. The bound proteins were separated by SDS-PAGE, and analysed by Western blotting.

\section{Antibody array screening, Western blotting, and immunoprecipitation assay}

TCE were prepared with lysis buffer ( $50 \mathrm{mM}$ Tris $\mathrm{Hcl}$ pH 7.5, $5 \mathrm{mM}$ EDTA, $300 \mathrm{mM} \mathrm{NaCl}, 150 \mathrm{mM} \mathrm{KCl}, 1 \mathrm{mM}$ dithiothreitol, $1 \%$ Nonidet P40, and a mix of protease inhibitors). We used an antibody array filter (Hypromatrix Incorporation) in which 100 polyclonal or monoclonal antibodies, including antibodies against well-studied proteins involved in cell cycle regulation, apoptosis, and signal transduction pathways are immobilized on a membrane, at predetermined positions, and retain their capabilities of recognizing and capturing antigens. After incubation with a TCE from 293 cells overexpressing HA-HMGA1b, immunoblot assay was performed following the manufacturer's instructions using an HRP-conjugated antiHA antibody (Santa Cruz Biotechnology Inc.), followed by enhanced chemiluminescence (ECL, Amersham Pharmacia) to detect the captured proteins.

For co-immunoprecipitation experiments, antigens and Abs were incubated for $3 \mathrm{~h}$ and then supplemented with protein A-sepharose or Gsepharose beads (Pharmacia Biotech). After $1 \mathrm{~h}$, the beads were collected and washed five times with lysis buffer, and boiled in Laemmli sample buffer for immunoblotting analysis. Protein extracts and immunoprecipitated pellets were separated by SDS-PAGE, and then transferred onto Immobilon-P Transfer membranes (Millipore) or stained with blue Coomassie. Membranes were blocked with $5 \%$ non-fat milk proteins and incubated with Abs at the appropriate dilutions. The filters were incubated with horseradish peroxidase-conjugated secondary Abs, and the signals were detected with ECL. The Abs used for immunoprecipitation and Western blotting were: anti-FLAG monoclonal Ab (Sigma); anti-HA 12CA5 monoclonal Ab (Roche); anti-p53 Fl393 polyclonal Ab and anti-p53 D01 monoclonal Ab (Santa Cruz Biotechnology Inc.); anti-HMGA1 are polyclonal $A b$ raised against a synthetic peptide located in the 
$\mathrm{NH}_{2}$-terminal region. Anti- $\gamma$-tubulin (Santa Cruz Biotechnology Inc.) was used for loading control.

\section{Electrophoretic mobility shift assay (EMSA)}

DNA binding assays with the recombinant proteins were performed as previously described. ${ }^{4}$ Briefly, $50 \mathrm{ng}$ of His-HMGA $1 \mathrm{~b}$ recombinant protein were incubated with radio-labelled double-strand oligonucleotide, corresponding to region spanning bases $-441 /-500$ of the human bax promoter region (hbaxpr), and the mutated oligonucleotide, in which the p53-binding site has been deleted (hbaxprdel). His-HMGA1b protein was incubated in a solution made of $20 \mathrm{mM}$ HEPES pH 7.9, $40 \mathrm{mM} \mathrm{KCl}$, $0.1 \mathrm{mM}$ EDTA, $0.5 \mathrm{mM} \mathrm{MgCl} 2,0.5 \mathrm{mM}$ DTT, $0.1 \mathrm{mM} \mathrm{PMSF}, 0.5 \mu \mathrm{g}$ poly(dC-dG), $2 \mu \mathrm{g} \mathrm{BSA}$ and $10 \%$ glycerol, to a final volume of $20 \mu \mathrm{l}$, for $10 \mathrm{~min}$ at room temperature. The samples were incubated for $15 \mathrm{~min}$ after addition of $2.5 \mathrm{fmol}$ of a ${ }^{32} \mathrm{P}$-end-labelled oligonucleotide (specific activity, $8000-20000 \mathrm{cpm} / \mathrm{fmol}$ ). A 100-fold molar excess of unlabelled oligonucleotide was added as specific competitor. The DNA-protein complexes were resolved on $6 \%$ nondenaturing acrylamide gels and visualized by exposure to autoradiographic films.

\section{Chromatin immunoprecipitation (Chlp) and Re-Chlp assays}

Briefly, $5 \times 10^{6} \mathrm{H} 1299$ cells were cross-linked using $1 \%$ formaldehyde for $10 \mathrm{~min}$ at room temperature. The reaction was stopped with glycine $0.125 \mathrm{M}$ for $5 \mathrm{~min}$. The cells were washed twice with cold PBS, harvested, and lysed sequentially by $10 \mathrm{~min}$ in ice and $5 \mathrm{~min}$ centrifugation at $3000 \times g$ at $4^{\circ} \mathrm{C}$ with $1 \mathrm{ml}$ buffer $\mathrm{A}$ (10 $\mathrm{mM} \mathrm{HEPES} \mathrm{pH} 8,10 \mathrm{mM}$ EDTA pH 8.0, 0.5 mM EGTA pH 8.0, 0.25\% Triton X-100 and protease inhibitors), and then with $1 \mathrm{ml}$ buffer $B(10 \mathrm{mM}$ HEPES pH 8.0, $200 \mathrm{mM} \mathrm{NaCl} 1 \mathrm{mM}$ EDTA pH 8.0, 0.5 mM EGTA pH 8.0, 0.01\% Triton X-100 and protease inhibitors). The pellets were then resuspended in $200 \mu \mathrm{l}$ of lysis buffer (10 mM EDTA, $50 \mathrm{mM}$ Tris-HCl pH 8.0, 1\% SDS and protease inhibitors), and sonicated five times for $30 \mathrm{~s}$ at maximum settings, obtaining fragments between 0.3 and $1.0 \mathrm{~kb}$. The samples were cleared by centrifugation at 14000 r.p.m. for $15 \mathrm{~min}$. After centrifugation, $20 \mu \mathrm{l}$ of the supernatants were used as inputs, and the other part of the samples diluted 2.5 -fold in Ip buffer ( $100 \mathrm{mM} \mathrm{NaCl}, 2 \mathrm{mM}$ EDTA pH 8.0, $20 \mathrm{mM}$ Tris- $\mathrm{HCl}$ pH 8.0, 0.5\% Triton $\mathrm{X}-100$ and protease inhibitors). The samples were subjected to immunoprecipitation with specific antibody (anti-HMGA1 described in the previous section, and anti-p53 sheep polyclonal Ab7 from Calbiochem) after $2 \mathrm{~h}$ preclearing at $4^{\circ} \mathrm{C}$ with Protein A Sepharose or Protein G Sepharose/BSA/Salmon Sperma (Upstate). Precipitates were washed

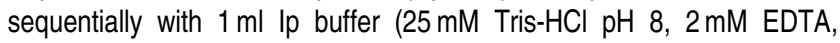
$150 \mathrm{mM} \mathrm{NaCl}, 1 \%$ Triton X-100, 0.1\% SDS), $1 \mathrm{ml}$ Wash buffer 1 (25 mM Tris- $\mathrm{HCl}$ pH $8.2 \mathrm{mM}$ EDTA, $500 \mathrm{mM} \mathrm{NaCl}, 1 \%$ Triton X-100, 0.1\% SDS), $1 \mathrm{ml}$ Wash buffer $2(0.25 \mathrm{M} \mathrm{LiCl}, 1 \% \mathrm{NP} 40,1 \% \mathrm{Na}$ deoxycholate, $1 \mathrm{mM}$ EDTA, $10 \mathrm{mM}$ Tris- $\mathrm{HCl} \mathrm{pH}$ 8), and then twice with $1 \mathrm{mM}$ EDTA, $10 \mathrm{mM}$ Tris- $\mathrm{HCl} \mathrm{pH} \mathrm{8.0.} \mathrm{Precipitated} \mathrm{chromatin} \mathrm{complexes} \mathrm{were} \mathrm{removed} \mathrm{from} \mathrm{the}$ beads through $15 \mathrm{~min}$ incubation with $250 \mu \mathrm{l}$ of $1 \%$ SDS, $0.1 \mathrm{M} \mathrm{NaHCO}_{3}$. This step was repeated twice.

In Re-Chip experiments, complexes were eluted by incubation for $30 \mathrm{~min}$ at $37^{\circ} \mathrm{C}$ in $250 \mu \mathrm{l}$ of Re-lp buffer ( $2 \mathrm{mM} \mathrm{DTT}, 1 \%$ Triton X-100, $2 \mathrm{mM}$ EDTA, $150 \mathrm{mM} \mathrm{NaCl}, 20 \mathrm{mM}$ Tris- $\mathrm{HCl} \mathrm{pH} \mathrm{8.1)} \mathrm{and} \mathrm{then} \mathrm{diluted} \mathrm{four-}$ fold in Re-Ip dilution buffer (1\% Triton X-100, 2 mM EDTA, $150 \mathrm{mM} \mathrm{NaCl}$, $20 \mathrm{mM}$ Tris- $\mathrm{HCl} \mathrm{pH} 8.1$ and protease inhibitors), and subjected again to the Chlp procedure. Crosslink was reversed by an overnight incubation at $65^{\circ} \mathrm{C}$ with $20 \mu \mathrm{l}$ of $5 \mathrm{M} \mathrm{NaCl}$. Then were added $10 \mu \mathrm{l} 0.5 \mathrm{mM}$ EDTA, $20 \mu \mathrm{l}$
$1 \mathrm{M}$ Tris-HCl pH 6.5 and $20 \mu \mathrm{g}$ of Proteinase $\mathrm{K}$, and incubated for $1 \mathrm{~h}$ at $45^{\circ} \mathrm{C}$. DNA was purified by Phenol/ $\mathrm{CHCl}_{3}$, and precipitated by two volumes of ethanol in the presence of tRNA. PCR was performed using specific primers: h-bax-pr-up 5'-TAATCCCAGCGCTTTGGAAG-3'; h-baxpr-dw 5'-GTCCAATCGCAGCTCTAATG-3'; h-GAPDH-pr-up 5'-GTAT TCCCCCAGGTTTACATG-3'; h-GAPDH-pr-dw-5'-TTCTCCATGGTGGT GAAGAC-3'.

\section{Recombinant adenoviruses and adenoviral infection}

The E1/E3 defective recombinant adenovirus dl70.3 (dl) and its Adp53 derivative, in which the human wtp53 cDNA was cloned, ${ }^{38}$ were amplified and titrated on 293 cells. Adenoviral infection was performed using 60 plaque forming units/cell of recombinant adenovirus. ${ }^{39}$

\section{Cell viability and TUNEL assay}

Both floating and adherent cells were collected and counted in a hemocytometer after the addition of Trypan blue. The percentage of dead cells, that is, number of blue cells/total cell number, was determined by scoring 100 cells per chamber three times. Cell numbers were determined in duplicate.

For TUNEL assay, both floating and adherent cells were spun onto slides by cytocentrifugation. After fixing in $4 \%$ formaldehyde in PBS, cells were incubated with fluorescein-conjugated dUTP terminal deoxynucleotide transferase mixture for TUNEL reaction (Roche), according to the manufacturer's instructions, counterstained with $1 \mu \mathrm{g} / \mathrm{ml}$ of Hoechst 33258 for 2 min and mounted with a coverslip in $25 \%$ glycerol in PBS. At least 400 cells were counted in each plate.

\section{Acknowledgements}

We are grateful to Jean Ann Gilder (Scientific Communication) for editing the text, and to Barbara Cecchinelli for GST-p53 vectors. We are grateful to Giorgia Bracaglia for providing her data about the effects exerted from HMGA1a isoform on p53 apoptotic activity. We thank the Associazione Italiana Ricerca sul Cancro (AIRC), the Progetto Finalizzato 'Biotecnologie' of the CNR, the MURST projects 'Terapie antineoplastiche innovative' and 'Piani di Potenziamento della Rete Scientifica e Tecnologica', the Associazione Partenopea per le Ricerche Oncologiche (APRO) and the Ministero della Salute for their support. CR is recipient of a fellowship from Fondazione Italiana per la Ricerca sul Cancro (FIRC).

\section{References}

1. Grosschedl R, Giese K and Pagel J (1994) HMG domain proteins: architectural elements in the assembly of nucleoprotein structures. Trends Genet. 10: 38-42

2. Reeves $R(2000)$ Structure and function of the $H M G I(Y)$ family of architectural transcription factors. Environ. Health Perspect. 108: 803-809

3. Reeves R and Nissen MS (1990) The A-T-DNA-binding domain of mammalian high mobility group I chromosomal proteins. A novel peptide motif for recognizing DNA structure. J. Biol. Chem. 265: 8573-85782

4. Thanos D and Maniatis T (1995) Virus induction of human IFN beta gene expression requires the assembly of an enhanceosome. Cell 83: 1091-1100

5. Zhou X, Benson KF, Ashar HR and Chada K (1995) Mutation responsible for the mouse pygmy phenotype in the developmentally regulated factor $\mathrm{HMGI}-\mathrm{C}$. Nature 376: 771-774

6. Chiappetta G, Avantaggiato V, Visconti R, Fedele M, Battista S, Trapasso F, Merciai BM, Fidanza V, Giancotti V, Santoro M, Simeone A and Fusco A (1996) 
High level expression of the HMGA1 gene during embryonic development. Oncogene 13: 2439-2446

7. Giancotti V, Berlingieri MT, Di Fiore PP, Fusco A, Vecchio G and CraneRobinson $C$ (1985) Changes in nuclear proteins on transformation of rat epithelial thyroid cells by a murine sarcoma retrovirus. Cancer Res. 45: 60516057

8. Giancotti V, Pani B, D'Andrea P, Berlingieri MT, Di Fiore PP, Fusco A, Vecchio G, Philp R, Crane-Robinson C and Nicolas RH (1987) Elevated levels of a specific class of nuclear phosphoroproteins in cells transformed with ras and v-mos oncogenes and by co-transfection with c-myc and Polyoma Middle T genes. EMBO J. 6: 1981-1987

9. Giancotti V, Buratti E, Perissin L, Zorzet S, Balmain A, Portella G, Fusco A and Goodwin GH (1989) Analysis of the HMGI nuclear proteins in mouse neoplastic cells induced by different procedures. Exp. Cell Res. 184: 538-545

10. Chiappetta G, Bandiera A, Berlingieri MT, Visconti R, Manfioletti G, Battista S, Martinez-Tello FJ, Santoro M, Giancotti V and Fusco A (1995) The expression of the high mobility group HMGA1 proteins correlates with the malignant phenotype of human thyroid neoplasms. Oncogene 10: 1307-1314

11. Chiappetta G, Tallini G, De Biasio MC, Manfioletti G, Martinez-Tello FJ, Pentimalli F, de Nigris F, Mastro A, Botti G, Fedele M, Berger N, Santoro M, Giancotti V and Fusco A (1998) Detection of high mobility group I HMGI(Y) protein in the diagnosis of thyroid tumors: $\mathrm{HMGI}(\mathrm{Y})$ expression represents a potential diagnostic indicator of carcinoma. Cancer Res. 58: 4193-4198

12. Fedele M, Bandiera A, Chiappetta G, Battista S, Viglietto G, Manfioletti G, Casamassimi A, Santoro M, Giancotti V and Fusco A (1996) Human colorectal carcinomas express high levels of high mobility group $\mathrm{HMGI}(\mathrm{Y})$ proteins. Cancer Res. 56: 1896-1901

13. Abe N, Watanabe T, Sugiyama M, Uchimura H, Chiappetta G, Fusco A and Atomi $Y$ (1999) Determination of high mobility group I(Y) expression level in colorectal neoplasias: a potential diagnostic marker. Cancer Res. 59: 1169-1174

14. Chiappetta G, Manfioletti G, Pentimalli F, Abe N, Di Bonito M, Vento MT, Giuliano A, Fedele M, Viglietto G, Santoro M, Watanabe T, Giancotti $V$ and Fusco A (2001) High mobility group HMGI(Y) protein expression in human colorectal hyperplastic and neoplastic diseases. Int. J. Cancer 91: 147-151

15. Tamimi Y, van der Poel HG, Denyn MM, Umbas R, Karthaus HF, Debruyne FM and Schalken JA (1993) Increased expression of high mobility group protein $\mathrm{I}(\mathrm{Y})$ in high grade prostatic cancer determined by in situ hybridization. Cancer Res. 53: 5512-5516

16. Abe N, Watanabe T, Izumisato Y, Masaki T, Mori T, Sugiyama M, Chiappetta G, Fusco A, Fujioka $Y$ and Atomi $Y$ (2002) Diagnostic significance of high mobility group I(Y) protein expression in intraductal papillary mucinous tumors of the pancreas. Pancreas 25: 198-204

17. Bandiera A, Bonifacio D, Manfioletti G, Mantovani F, Rustighi A, Zanconati F, Fusco A, Di Bonito L and Giancotti V (1998) Expression of HMGI(Y) proteins in squamous intraepithelial and invasive lesions of the uterine cervix. Cancer Res. 58: $426-431$

18. Masciullo V, Baldassarre $G$, Pentimalli $F$, Berlingieri MT, Boccia A, Chiappetta G, Palazzo J, Manfioletti G, Giancotti V, Viglietto G, Scambia G and Fusco A (2003) HMGA1 protein over-expression is a frequent feature of epithelial ovarian carcinomas. Carcinogenesis 24: 1191-1198

19. Baldassarre G, Battista S, Belletti B, Thakur S, Pentimalli F, Trapasso F, Fedele M, Pierantoni G, Croce CM and Fusco A (2003) Negative regulation of BRCA1 gene expression by HMGA1 proteins accounts for the reduced BRCA1 protein levels in sporadic breast carcinoma. Mol. Cell. Biol. 23: 2225-2238
20. Berlingieri MT, Manfioletti G, Santoro M, Bandiera A, Visconti R, Giancotti V and Fusco A (1995) Inhibition of HMGI-C protein synthesis suppresses retrovirally induced neoplastic transformation of rat thyroid cells. Mol. Cell. Biol. 15: $1545-1553$

21. Berlingieri MT, Pierantoni GM, Giancotti V, Santoro M and Fusco A (2002) Thyroid cell transformation requires the expression of the HMGA1 proteins. Oncogene 21: 2971-2980

22. Scala S, Portella G, Fedele M, Chiappetta G and Fusco A (2000) Adenovirusmediated suppression of $\mathrm{HMGI}(\mathrm{Y})$ protein synthesis as potential therapy of human malignant neoplasias. Proc. Natl. Acad. Sci. USA 11: 4256-4261

23. Lane DP (1992) Cancer: p53, guardian of the genome. Nature 358: 15-16

24. Vousden KH (2000) p53: death star. Cell 103: 691-694

25. Vogelstein B, Lane D and Levine AJ (2000) Surfing the p53 network. Nature 408: $307-310$

26. Schmitt CA, Fridman JS, Yang M, Baranov E, Hofmann RM and Lowe SW (2002) Dissecting p53 tumor suppressor functions in vivo. Cancer Cell 1: 289-298

27. Gottlieb TM and Oren M (1996) p53 in growth control and neoplasia. Biochim. Biophys. Acta 1287: 77-102; Review

28. Zhao R, Gish K, Murphy M, Yin Y, Notterman D, Hoffman WH, Tom E, Mack DH and Levine AJ (2000) Analysis of p53-regulated gene expression patterns using oligonucleotide arrays. Genes Dev. 14: 981-993

29. Bunz F, Dutriaux A, Lengauer C, Waldman T, Zhou S, Brown JP, Sedivy JM, Kinzler KW and Vogelstein B (1998) Requirement for p53 and p21 to sustain G2 arrest after DNA damage. Science 282: 1497-1501

30. Hupp TR, Meek DW, Midgley CA and Lane DP (1992) Regulation of the specific DNA binding function of $\mathrm{p53}$. Cell $71: 875-886$

31. Ito $T$ (1992) Unique association of p53 mutations with undifferentiated but not with differentiated carcinomas of the thyroid gland. Cancer Res 52: 1369-1371

32. Gao X, Porter AT, Grignon DJ, Pontes JE and Honn KV (1997) Diagnostic and prognostic markers for human prostate cancer. Prostate 31: 264-281

33. Jayaraman L, Moorthy NC, Murthy KG, Manley JL, Bustin M and Prives C (1998) High mobility group protein-1 (HMG-1) is a unique activator of p53. Genes Dev. 15: 462-472

34. Stros M, Ozaki T, Bacikova A, Kageyama H and Nakagawara A (2002) HMGB1 and HMGB2 cell-specifically down-regulate the p53- and p73-dependent sequence-specific transactivation from the human Bax gene promoter. J. Biol. Chem. 277: 7157-7164

35. Bustin M and Reeves R (1996) High-mobility-group chromosomal proteins: architectural components that facilitate chromatin function. Prog. Nucleic Acid Res. Mol. Biol. 54: 35-100. Review.

36. D'Orazi G, Cecchinelli B, Bruno T, Manni I, Higashimoto Y, Saito S, Gostissa M, Coen S, Marchetti A, Del Sal G, Piaggio G, Fanciulli M, Appella E and Soddu S (2002) Homeodomain-interacting protein kinase-2 phosphorylates p53 at Ser 46 and mediates apoptosis. Nat. Cell Biol. 4: 11-19

37. Pierantoni GM, Fedele M, Pentimalli F, Benvenuto G, Pero R, Viglietto G, Santoro M, Chiariotti L and Fusco A (2001) High mobility group I (Y) proteins bind HIPK2, a serine-threonine kinase protein which inhibits cell growth. Oncogene. 20: 6132-6141

38. Bacchetti S and Graham F (1993) Inhibition of cell proliferation by an adenovirus vector expressing the human wild type p53 protein. Int. J. Oncol. 3 : $781-788$

39. D'Orazi G, Marchetti A, Crescenzi M, Coen S, Sacchi A and Soddu S (2000) Exogenous wt-p53 protein is active in transformed cells but not in their nontransformed counterparts: implications for cancer gene therapy without tumor targeting. J. Gene Med. 2: 11-21 


\title{
Retraction
}

\section{Retraction: High Mobility Group A1 (HMGA1) proteins interact with p53 and inhibit its apoptotic activity}

\author{
GM Pierantoni, C Rinaldo, F Esposito, M Mottolese, S Soddu and A Fusco
}

Cell Death and Differentiation advance online publication, 6 December 2013; doi:10.1038/cdd.2013.183

Retraction to: Cell Death and Differentiation (2006) 13, 1554-1563; doi:10.1038/sj.cdd.4401839

It has come to our attention that multiple bands in Figure 1e and lanes in Figure $3 a$ have been inappropriately duplicated.
The authors are unable to provide the original source files that were used to generate these data and they have all agreed to retract this article. The conclusions of the paper have been confirmed by subsequent papers. 